\title{
The war from both sides: How Dutch and German visitors experience an exhibit of Second World War stories
}

\begin{abstract}
At the 75th anniversary of the end of the Second World War, questions arise if contemporary audiences still find historical accounts relevant. Fundamental to understanding the relevance of stories from the war is assessing their emotional impact on leisure participants from various social groups. We used the social identity theory framework to assess differences in emotional reactions of Dutch and German visitors to stories of the Second World War presented at a Dutch museum exhibit. Emotional reactions were measured using physiological signals of heart rate and heart rate variability as well as self-report. Emotions experienced were mixed and often, but not always, different between Dutch and German participants. Patterns in the physiological and self-report data differed. Many of the significant differences were generally consistent with a collective guilt account of German social identity, but the findings as a whole were more complex than could be predicted by existing social identity accounts. Specifically, participants did not simply categorize themselves with either national or human identities of characters based on what their respective stories emphasized. We conclude that stories of the Second World War are still relevant, but touch on audiences' nationalities in a complex way, beyond simple historical categories.
\end{abstract}

Keywords: Second World War, experience, emotions, heart rate, heart rate variability, social identity 


\section{The war from both sides: How Dutch and German visitors experience an exhibit of Second World War stories}

1. Introduction

In May of 2020, the Netherlands celebrated the $75^{\text {th }}$ anniversary of liberation at the end of the Second World War. Besides being attenuated by social distancing, celebrations were tinged with a sense of caution, as few living witnesses of the war remain. Fear was expressed that younger people are losing touch with the historical significance of the war, and the associated values of self-determination, peace, and democracy. As a result, public institutions in the Netherlands, such as museums and destination marketing organizations, have invested in leisure experiences which translate Second World War history into stories and rituals with contemporary meaning. Investments in leisure experiences related to the Second World War are in line with the rising popularity of visits to, and research on, cultural heritage sites related to war and suffering (Hartmann 2014).

An example of such a leisure experience is the exhibit the Netherlands During World War II at the War Museum Overloon. In this exhibit, set against a background of wartime artifacts from daily life, eight interactive displays tell stories of eight characters who the war touched in some way: the Nazi commissioner governing the country, the Dutch queen, a woman who wrote detailed letters about daily life during the war, a collaborator, a young Jewish girl, an artist fighting in the resistance, a student interned in a labor camp, and a toddler suffering from starvation. Some of their stories are told in movies several minutes long. Other stories are divided in short video segments, which visitors must interact with by moving or pushing buttons to advance. Still others use only audio, with no images.

The museum is located near the Dutch-German border, and receives a substantial proportion of German visitors, although the stories are clearly developed from a Dutch perspective. Hence, the experience of viewing the exhibit may be different for Dutch and German visitors, with differing identifications of one's own heritage in the exhibit content (Poria et al. 2003), and thus differing personal identification with the exhibits themselves. As such exhibits depend on emotional impact in a contemporary audience, and the museum enjoys an increasing proportion of German visitors, it is crucial to understand differences in how Dutch and German visitors' emotions develop from story to story.

Emotional effects of stories within exhibits partly depend on identifying with the character in each story. It is not obvious, however, to what extent present-day German and Dutch visitors, respectively, identify with the wartime national identities of the characters portrayed. Differences in personal identification have been highlighted in previous research on heritage tourism (Poria et al. 2003). The economic and social ties built by the European Union may render other identities, such as a shared human identity, more salient. Different identities expressed in the exhibit, explored through the lens of social identity theory (Tajfel 1974, 1979) and its offshoot, selfcategorization theory (Turner et al. 1987), may explain potential differences in how Dutch and German visitors experience each story. 
In the present study, we review research on social identity theory and its application to leisure to frame our examination of how Dutch and German visitors experience the Netherlands during World War II. Then, we analyze novel biometric and location tracking data to bring the emotions of 52 Dutch and 17 German visitors to light. Our study used wearables and smartphones in addition to questionnaires to measure Dutch and German visitors' emotions while they went through the exhibit at their own pace, creating a spatio-temporally detailed, naturalistic, ecologically valid measurement of their visits. In our Findings, we compare average levels of physiological markers of emotion at each exhibit between Dutch and German visitors, as well as examining differences in their selfreported emotions just after their visit. Finally, in our Discussion, we discuss several intergroup differences we found in light of social identity theory, and what visitors' possible identification with the characters portrayed means for leisure experiences linked to World War II in Europe.

\section{Literature review}

In the most general terms, our research is about the way people react to stories of a war that happened before their lifetime, and if coming from nations on opposite sides of that conflict makes a difference in their reactions. This inquiry touches on the way people identify with a national group, especially under the legacy of armed conflict, and on emotion as a potential outcome of that process. Such identification is known to be important for the experiences and outcomes of visits to cultural heritage sites (Poria et al. 2003). Thus, our literature review focuses on people's emotional reactions to stories which highlight certain historical social identities. To make sense of these reactions, two theoretical perspectives are needed: social identity theory, which explains emotional reactions to national identities, and a model of leisure experience which explains the key role of emotions.

\subsection{Social identity theory}

To give a full review of research on social identity theory, which has now existed for nearly 45 years, is beyond the scope of the present article. Introductory reviews exist (e.g., Hornsey 2008), as do worthwhile theoretical debates situating social identity theory next to its sociological cousin, identity theory (Stets and Burke 2000; Hogg et al. 1995). We instead briefly define social identity theory and its branching into self-categorization theory, then summarize some key applications of the theory to the legacies of war as well as to leisure experiences.

Despite originating is social psychology, which takes the individual as the unit of analysis, social identity theory (Tajfel 1974, 1979) approaches individuals from the perspective of their membership in a social group. Tajfel and Turner (1979) define a social group as a group of individuals who indentify themselves as belonging to specific, shared group identity. The social group is also recognized as such by outsiders. The psychological hallmark of a social group is "seeing the self and others in terms of their representativeness of contrasting social groups and categories" (Abrams and Hogg 2010, p.179). According to Tajfel (1979), a social group is represented in an individual's mind by a cognitive element (i.e. knowing that (s)he is part of a given social group), an evaluative element (i.e. judging whether being part of that group is something good or bad), and an emotional element (i.e. experiencing positive or negative emotions based on membership and evaluation). 
Ashforth and Mael (1989) explain that social groups are formed on the basis of "prototypical characteristics" of the individuals within those groups (p. 20). In other words, each individual in society is assigned to a social group by themselves or others, based on the the extent to which individual characteristics match those of the social group (Ashfort \& Mael, 1989). Those personal characteristics could be, for example, values, abilities, interests, and physiological traits (Ashfort \& Mael, 1989). Individuals usually have characteristics that match with more than one social group. Therefore, a hierarchy may be identified where at any given place and time, membership in a particular group is more salient than membership in other groups (Tajfel \& Turner, 1979; Tajfel, 1979; Ashfort \& Mael, 1989).

A development of social identity theory, termed self-categorization theory, recognized that membership in social groups forms only one level of a person's identity. Beneath this "intermediate" social identity, there also exists a "subordinate" personal identity, consisting of individual characteristics such as personality that distinguish an individual (Hornsey 2008, p.208). Furthermore, there is also a "superordinate" human identity, whereby an individual identifies with all fellow humans. Just as different social groups have different salience depending on context, also different levels of identity_-personal, social, and human — have different salience depending on context. Research on individuals' emotional reactions to the legacy of war has addressed different salience of selfcategorization levels to explain different reactions to similar historical facts.

\subsection{Social identity and self-categorization as a legacy of war}

A robust body of research applies social identity theory to the legacies of war. Armed conflict creates intense polarization between regional, national, or ethnic groups, leading to highly salient in-group and out-group identities in participants. A clear conclusion from this research is that war reinforces national identities long after it has ended, wherein "reminders of past suffering based on group membership encourages categorization in intergroup terms, which then promotes ingroup-favoring and conflict-maintaining responses in the present" (Wohl \& Branscombe, p.285). In fact, in the context of Germany, Seiffge-Krenke and Haid (2012) write of a "transgenerational irritation" that contemporary youth in Germany may feel about the Second World War (p.37). According to Wohl and Branscombe (2004), collective guilt for the Holocaust has been assigned to Germans as a social group. This association leads to strong responses based on social identity (Wohl \& Branscombe, 2004, p.286). There is less research on this topic in the Netherlands, but similar effects are seen among non-immigrant Dutch identities compared to those of Dutch immigrant nationalities during economic downturns (Poppe 2001).

There is an optimistic side to the story as well, however. Several studies demonstrate that when the superordinate category of humanity is emphasized, individuals can identify with groups on both sides of a conflict as fellow humans rather than taking the social identity of "their" side (e.g., Zebel et al. 2009; Wohl and Branscombe 2005). Furthermore, in contemporary German and Dutch societies, there is a social level of identity above nationality - the identity associated with the European continent and the European Union (EU) as an institution. Although in both countries, there exist highly polarized debates about the value of the EU, there is broad agreement that social identities have altered beyond the stark national boundaries of the Second World War era, and that a 
European identity exists to some extent in many Dutch and German minds. According to Risse (2001, p.200), development of the EU has given "challenges to given nation-state identities."

In sum, there is reason to expect that stories of the Second World War which do not strongly emphasize national identities would trigger emotions that do not necessarily differ by nationality. This possibility has not been examined in a leisure context, however. In fact, most social identity research uses scenario-based experimental designs which reveal the psychological mechanisms at play, but not the relative importance of these mechanisms in people's daily lives. Leisure experiences, such as a visit to a museum, offer an interesting context to examine the consequences of social identity in a naturalistic setting.

According to an excellent review by Hartmann (2014), visits to museums and heritage sites related to war and suffering are not only increasingly popular, but increasingly common subjects for research. The assignment of victims or perpetrators identities to social groups in this conxtext is, according to Hartmann, often discussed by scholars, but existing research stops short of comparing experiences of portrayed social groups based on social identity. Thus, we turn our focus to extant leisure research on social identity.

\subsection{Social identity research in leisure}

While the concept of identity, particularly marginalized and contested identity categories, have received extensive attention from leisure researchers, only a handful of studies have applied social identity theory and selfcategorization theory to leisure contexts. The contexts studied have usually involved sports participation or fandom, including football (Stodolska and Tainsky 2015; Jones 2000), cycling (Mueller et al. 2019), basketball (Laverie and Arnett 2000), and roller derby (Liu et al. 2016). Variables linked with social identities have often included constraints (Mueller et al. 2019; Jones 2000) or serious leisure status (Liu et al. 2016; Jones 2000). While emotions do sometimes show up as a variable (Liu et al. 2016), emotions have not been studied as a consequence of social identity within a leisure experience.

A notable exception, which forms a concrete precedent for the present study, is Gieling and Ong's (2016) study of visitor experience at another Dutch museum focused on the Second World War, the Airborne Museum Hartenstein. Gieling and Ong identified the importance of understanding how museum exhibits about the war can elevate the salience of a national identity, and how this process spurs emotional reactions in visitors. Interestingly, they found that salience of national identity was unrelated to visitors' (recalled) emotions. Unfortunately, their findings are constrained by two limitations which our study aims to address.

As with other leisure research applying social identity theory, Gieling and Ong (2016) limit their research to a single social group. This is in sharp contrast to typical social psychology studies of social identity, which use two groups of participants to show that effects are independent of intragroup context (e.g., Wohl and Branscombe 2005). Mueller et al. (2019) point out this limitation in their own research, urging that "future research should explore the role of social identity among less clear social groups to evaluate its effect given a less clearly defined ingroup." By researching the link between emotions and social identity in two national groups with somtimes ambiguous stimuli, we hope to deploy the strengths of both social psychology research, which typically uses two or more groups, and leisure research, which frequently occurs in naturalistic settings. 
A second shortcoming in leisure research applying social identity theory is that when emotions are considered, they are typically recorded after the fact using cross-sectional self-response questionnaires (Gieling and Ong 2016; Liu et al. 2016). A study comparing visitors who identify with heritage to differing degrees faces a similar limitation (Poria et al. 2003). While cross-sectional questionnaire research is considered a valid and reliable method of measuring emotional experience, in the case of complex experiences such as leisure, it misses the temporal dynamics of emotion, and may include recall biases. Recent theoretical work on emotions in leisure experiences points to potential solutions of these limitations.

\subsection{Emotions in leisure experiences}

Emotions are usually defined as intense, short-lived, complex responses to personally meaningful stimuli (Rosenberg 1998). The importance of emotions in leisure experiences has been widely recognized. Emotions are a source of value and meaning in leisure experiences (Mitas et al. 2011) and predict valuable outcomes such as recommendation, revisiting, and well-being (Mitas et al. 2017). Measuring how emotions mediate the outcome of leisure experiences is difficult, however. Emotions are recalled quite differently after an experience from how they are felt in the moment (Wirtz et al. 2003; Zajchowski et al. 2016). Thus, Bastiaansen et al. (2019) developed a model of leisure, tourism, and hospitality experiences wherein experiences are divided into discrete episodes. Each episode is recalled, and influences downstream behavior, only if it features enough emotion to be appraised as meaningful by the individual. Thus, the rise and fall of emotions over the course of an experience influences how that experience ultimately creates meaning and influences behavior. The model thus responds to the call of Duerden et al. (2015) to identify which mechanism of experience outcomes may be most important.

Understanding how emotions develop over the course of a specific experience requires measuring emotions as they happen. According to Bastiaansen et al. (2019), wearable measurement of peripheral physiological correlates of emotion, such as skin conductance and heart rate, provides a promisng new methodology for recording emotions over the course of experiences unobtrusively and with high temporal resolution. By using such techniques in the present study, we hope to bring a more complex picture of emotion-social identity interplay to the social identity and leisure literatures.

\subsection{Exhibition: The Netherlands During the World War II}

The War Museum Overloon exhibit the Netherlands During the World War II comprises an ideal context to assess the impact of leisure experiences related to the war on contemporary Europeans. While present understanding of leisure experiences suggest that emotions are key to comprehending behavioral outcomes, social identity theory suggests that identifying with characters in stories triggers emotional reactions. The Netherlands in the Second World War exhibit presents eight characters with differing levels of national and supraordinate (human) identity emphasis. Based on social identity theory, we expect that emotional reactions will be based on identifying with a character, although the content of those emotions may vary from collective guilt toward in-group perpetrators to anger toward out-group perpetrators or sadness toward (human) victims. More specifically, we expect that the strongest emotional reactions will occur when visitors identify a character as belonging to their in-group. When this 
in-group is based on nationality, visitors of that nationality could have stronger reactions. However, when the supraordinate category of humanity is emphasized, nationality of visitor should not make a difference in the reaction.

\section{Methods}

We took a three-fold approach to examining national differences in responses to stories of the Netherlands During the World War II. First, we summarized the content of the stories in the exhibit with the aim of identifying which group category (national or superordinate, i.e., human) was emphasized. Based on these summaries, guided by social identity theory, we generated hypotheses about whether visitor nationality would influence emotional reactions to each exhibit, and if so, which nationality (Dutch or German) would react more strongly. We tested these hypotheses using physiological and location data collected from 69 visitors in March, April, and May of 2019. Finally, we used specific emotion categories measured by self-response to probe significant national differences in the physiological data for their specific emotional content.

\subsection{Stories of the exhibit}

The eight stories of the exhibit transect occupied wartime Dutch society in terms of power and prominence. The progression of the exhibition takes the visitor from the character of highest power and prominence, the Nazi commissioner responsible for the occupied state, to an almost completely anonymous and powerless toddler on the brink of starvation. In the following summaries, we attempt to give the reader an impression of the exhibition, with a focus on (super)national identities that we use to predict emotional reactions. A photo of part of the exhibit (Figure 1) shows the atmosphere and visual language used in presenting the stories, while a map (Figure 2) displays the spatial progression of the stories.

\section{FIGURES 1 AND 2 ABOUT HERE}

\subsubsection{Arthur Seyss-Inquart was the Nazi commissioner responsible for governing the occupied Netherlands.} Originally Austrian, he is clearly identified with the German state, and portrayed as attempting to balance a nonconfrontational approach to the "germanic" Dutch people while satisfying belligerent, repressive elements in his own party. As Dutch people begin to resist the occupation, the tension between these two priorities increases.

Inquart's story is portrayed in photos and several audio segments, which play in sequence when buttons on the display are pressed. His character's national in-group is German, and is negatively portrayed, especially later in the story, as Inquart increasingly complies with militant supporters. Therefore, we predicted that German visitors would have stronger emotional reactions than Dutch to Inquart's story, possibly due to guilt that comes from identifying with a negatively portrayed in-group (Wohl and Branscombe 2005).

3.1.2. Arnolda Huizinga-Sannes was a 63-year homemaker in the Hague with two adult children, Cato and Menno. Menno is a photographer and lives nearby. Cato works as a nurse in South Africa. Huizinga-Sannes starts keeping a 
diary of daily life during the war as a historical record for Cato. The tone of the diary is one of righteous indignation against the occupation.

Visitors use buttons to advance through several audio segments of a voice actress reading from Sannes' diaries. The clear moralizing stance in the diary texts positions the Dutch as the in-group of this story, and the anger and defiance communicated link a strong emotional tone with this group. Therefore, we predicted that Dutch visitors would have stronger emotional reactions to her story, potentially comprised of anger or pride.

3.1.3. Queen Wilhelmina was the ceremonial Dutch head of state. As the German invasion approached capturing the entire Dutch government, Wilhelmina and ministers fled to England, from where they explained their actions in a radio broadcast.

As with the first two displays, visitors use buttons to advance through several audio segments from this broadcast. The display situates the visitor as a radio operator. Wilhelmina's in-group is Dutch, and this nationality is portrayed positively, with tones of defiance and pride. On the other hand, her flight to England was viewed as disloyal by some Dutch, and could still prompt such a reaction. Therefore, we predicted that Dutch visitors would have stronger emotional reactions to her story possibly due to positive or mixed emotions.

3.1.4. Gerhard Stroink was a professional soldier at the outbreak of war. He chose to collaborate with the Nazis, but experienced great disappointment in fighting for the German army, rather than for an explicitly Dutch unit aligned with Germany. He was eventually wounded and remained unapologetic, both in his choice of sides and in his resentment toward Germany for not letting Dutch collaborators fight under their own flag. After the war, he was tried and executed. The video concludes with his adult son expressing the burden of being a collaborator's child.

The display with Stroink's story story shows several sequential video segments. To advance through these, visitors are asked to express the choices they would make in his position by standing in different places in front of the display. The deliberately creates ambiguity in the visitor about which national group he belongs to. While his actions are generally portrayed negatively, this is also somewhat nuanced by his internal consistency. Therefore, we predicted that if visitors identified with Stroink to some extent, that identification would not correspond to a clear national category. Therefore, we expected to see no difference in Dutch and German emotional reactions to his story.

3.1.5. Helene Egger was a ten-year-old Jewish girl, living with her grandparents in Amsterdam at the outbreak of war. Over the course of the systematic pursuit and extermination of Jewish residents of the Netherlands, she loses her family members one by one, until she is left to hide with a peasant family until the end of the war. Her story concludes with her present-day self expressing sorrow and memories of her wartime losses.

The display with Egger's story is the only display which is not interactive. Visitors are shown the story in the form of a 5-minute documentary-style film. While various identities are portrayed in the story, the emphasis on the loss of family Egger faced accentuates the supraordinate category of humanity. We believed that visitors would 
mostly identify with Egger as a young person losing family members before they identified with her nationality, and thus Dutch and German visitors would show equally strong reactions to her story.

3.1.6. Gerrit Jan van der Veen was a sculptor. Because Nazi restrictions on Dutch society included extracting loyalty from artists, Veen chose to continue his work underground as well as joining the resistance. He makes a series of escalating choices which eventually lead to his capture and execution. His son, who was born shortly after his death, expresses both admiration and sadness at the conclusion of his story.

As with the earlier diplay of Stroink (the collaborator), Veen's story shows several sequential video segments. Once again, visitors are asked to express the choices they would make in his position by standing in different places in front of the display. Veen's Dutch identity in contrast to his German adversaries is clearly highlighted in the story, and his actions are positively portrayed. Thus, as with the story of Queen Wilhelmina, we expected Dutch visitors to identify themselves as the in-group at this display, and to have stronger emotional reactions due to positive emotions such as pride.

3.1.7. Wiek Slagter is a law student. He is conscripted to a German labor camp with his fellow students for refusing to swear loyalty to the occupation. At the labor camp, he carries out tasks which he describes as "not really hard, rather boring" on an automobile assembly line.

Slagter's story is displayed as a series of brief video and audio vignettes which are prompted by pressing buttons. While he is identified as Dutch and his oppressors as German, these identities are not emphasized to same extent as his identity as a student and as a young man. Furthermore, his story lacks the emotional drama of the other displays. Therefore, we expected Dutch and German visitors to show equal reactions to his story.

3.1.8. Corrie Holvast is a toddler living in Amsterdam during the "hunger winter" of 1944-1945, when logistical restrictions led to famine conditions in Dutch cities. She offers a portrait of life under these conditions, wherein illness and hunger were constant. This display consists of three video segments which visitors advance using buttons. National identities are completely absent from this display. In fact, the actions leading to the starvation conditions are not discussed. Thus, we expected Dutch and German visitors to show equal reactions to his story.

TABLE 1 ABOUT HERE

\subsection{Sample}

We used a non-probability intercept sample to collect responses. We collected data on weekends for reasons of efficiency, as visitation was concentrated on the weekends during the time of year when we collected data (March-May 2019). We also collected data on 1 May, which was a Wednesday, but also a national holiday in Germany. One of us (second author) along with one or two trained student assistants approached visitors as they passed the entry gates, which led directly to the Netherlands During World War II exhibit. Participants provided informed consent and were fitted with Empatica E4 wearable wristbands and Motorola Moto smartphones to record 
their heart rate and location within the exhibit, respectively. They were asked to fill out an intake questionnaire with demographic items, then to visit the exhibition at their own pace. Afterwards, we asked participants to complete a second questionnaire, this time reporting their emotions at the specific displays in the exhibit. Participants spent between 15 and 119 minutes at the exhibit.

Because the primary goal of our research was to compare Dutch and German reactions to the exhibit, we made back-translated questionnaires in both Dutch and German available in addition to English, and approached participants in either Dutch or German based on which language we heard them speaking. Nevertheless, we experienced a difference in reactions to our sampling approach. After the planned data collection had been completed, we had experienced a $75 \%$ refusal rate from German visitors, compared to $20 \%$ from Dutch visitors. Thus, we added an additional weekend of data collection during which we employed an additional, native German speaking research assistant. While this greatly reduced refusals from German visitors, the overall sample contained relatively few Germans (17, all of whom provided useable data) compared to Dutch (52, of whom 42 provided useable data). This sample distribution affords limited statistical power to detect differences between Dutch and German visitors.

Furthermore, we cannot rule out that our sub-sample of German visitors is relatively less representative of German visitors to the museum, because most of our German respondents (13 of 17) were collected during the last weekend of data collection, and we experienced a high refusal rate from German visitors on the weekends prior. Nevertheless, given the complexity and magnitude of the data collected from each participant, we feel our sample afforded us a unique opportunity to document and compare Dutch and German reactions to this exhibit.

\subsection{Measures}

\subsubsection{Demographics}

Before entering the exhibit, we asked participants to indicate their nationality (Dutch, German, or other) and gender (male, female, or other) using closed-response items. An open-response item asked participants' age.

\subsubsection{Location}

We asked each participant to carry a Motorola Moto E5 smartphone with an application designed by one of the authors during their visit. The application recorded signal strength from 25 Estimore Bluetooth beacons which were mounted throughout the exhibit at waist level. Three beacons were mounted at the display of each story. Due to the multitude of walls and display cases, 25 beacons were marginally sufficient for recording participants' location throughout the entire exhibit. Therefore, we created a script that estimated location based on the 3 nearest beacons, and subsequently eliminated data points that were not within the normal viewing field of each display.

\subsubsection{Physiological emotional reactions}

We used two measures of cardiovascular activity, heart rate and heart rate variability. These two signals correspond to the sympathetic ("fight or flight") and parasympathetic ("rest and digest") responses of the central nervous system which are engaged, respectively, when an emotional stimulus is sensed and subsequently processed (Mauss and Robinson 2009). The psychophysiology literature cautions against taking either metric as a one-to-one 
indicator of emotional activity, especially in situations where physical movement varies between indiviuals (Cacioppo et al. 2007). While we did not notice our participants varying dramatically in their physical movement through the exhibit, we cannot rule this out as a source of noise in our data. Numerous laboratory studies where emotions are induced in participants show increased heart rate in response to emotional stimuli, whether positive or negative, suggesting that heart rate is a reliable indicator of emotional arousal (Kreibig 2010). Findings on heart rate variability are somewhat less consistent, although the general consensus is that heart rate variability is somewhat more indicative of negative emotional arousal or distress specifically (Kreibig 2010). Heart rate variability has been mobilized to assess stress in the urban walking experience (i Agustí et al. 2019), but not in the leisure or tourism literature to our knowledge.

We recorded participants' heart rate using Empatica E4 wristbands. The wristbands use a photoplethysmograph sensor worn on top of the wrist to measure variation in blood volume as it passes to and from the hand with each heartbeat. The level of blood volume is measured at 32 occasions per second. Software within the wearable then identifies peaks in this signal and records realistic temporal distances (more than 0.3 and less than 2.0 seconds) between these peaks as inter-beat intervals. Using a moving 10-second window, heart rate is then averaged from the inter-beat intervals. Using this process, most of the serious motion artifacts in the raw photoplethysmograph signal are removed. We used the resulting $1 \mathrm{~Hz}$ heart rate data as our heart rate metric, as well as the basis for calculating heart rate variability.

Heart rate variability for short periods of time (less than 5 minutes) is best assessed using time-domain methods such as standard deviation of interbeat intervals, that is, the time duration between each successive pair of heartbeats (i Agustí et al. 2019). We divided 60 by the $1 \mathrm{~Hz}$ heart rate data to derive per-second estimates of interbeat intervals, and then used a moving 10 second window to calculate standard deviation for the 10 seconds around each per-second measurement. This way, we derived a per-second metric of heart rate variability. Standard deviation of interbeat intervals is one of the most common metrics of heart rate variability in the psychophysiology literature (Kreibig 2010).

\subsubsection{Self-reported emotions}

Emotions during leisure experiences are often assessed using a list of specific emotions (e.g., Gieling and Ong 2016). Participants are presented with a 5-point response scale on which participants indicate the extent to which they felt each emotion. While the specific emotion lists used vary, two criteria are important in selecting or modifying such lists from previous studies: the listed emotions must be comprehensible to participants, and the emotions must be relevant to the context in which they are measured. Because we wanted to ask about each display in the exhibit separately, we had to pay attention to a third criterion: the list needed to be brief, as participants who saw all eight displays would have to respond to it eight times. Thus, we took as a starting point the twelve-item Scale of Positive and Negative Experience (Diener et al. 2010), which contains six general emotion items that emphasize the valence of emotional reactions (good, bad, pleasant, unpleasant, positive, negative), and six specific emotions (happy, sad, angry, afraid, joyful, contented). Of these, we selected positive and negative as the clearest 
words indicating opposite ends of the dimension of valence, as well as three other negative terms we felt would be relevant in viewing this exhibit: bad, sad, and angry.

\subsection{Analysis}

Based on our interest in between-participant differences (Dutch compared to German) in within-participant change (the change in emotion from one story to another throughout the exhibit), mixed-effect linear models were constructed for heart rate and heart rate variability as outcomes. Predictors in our models included the eight stories, participants' nationality, and the interaction terms between each story and the nationality. These interaction terms represent the differences between Dutch and German participants at each of the eight stories, over and above average differences between the stories and the overall difference between Dutch and German participants. In other words, the models were set up to determine if nationality moderated the emotional response to each story.

We further examined significant differences between Dutch and German participants in heart rate and heart rate variability using self-report emotion data at each story. Here we used simple independent-samples T-tests, as these are typically the follow-up to more complex procedures with multiple outcome variables, such as a MANOVA, and we were interested in probing emotion- and story- specific differences rather than omnibus effects. We used Levene's tests at the 0.05 level to decide between using pooled or unequal variance estimates.

Because of the large number of T-tests involved (40), we interpreted the not only uncorrected p-values, but also corrected p-values under two multiple inference correction apporaches. We first applied a Bonferroni correction of the alpha level. We assumed each emotion across the eight stories to be a single "family" of tests, so we used the alpha of $0.05 / 8=0.00625$. Because the Bonferroni correction is sometimes criticized as conservative, we also implemented the Benjamin-Hochberg procedure for controlling the false discovery rate, for which the critical value is slightly higher for each subsequent comparison (Field et al. 2012; McDonald 2014).

\section{Findings}

Our sample comprised 69 visitors (Table 2). Of these, 17 (25\%) were German and 52 (75\%) were Dutch. There were more men $(40 ; 58 \%)$ than women $(29 ; 42 \%)$. The mean age was 40 ( $\mathrm{SD}=13$ years), with 33 participants (48\%) falling between the ages of 36 and 50, inclusive. Below, we explain the differences between physiological signals of emotion in Dutch and German participants across the eight stories studied, which are also visualized in maps of the exhibit (Figure 5). Then, we probe these differences using self-report data pertaining to specific emotions.

\section{TABLE 2 ABOUT HERE}

\subsection{Heart rate reactions to stories}

Figure 3 shows heart rate levels over the eight stories for Dutch and German participants. The model of heart rate as a function of nationality and story fit the data significantly better than a null model $(\mathrm{p}<0.0001$; Table 3). The goal of this model was to identify at which stories there was a difference between Dutch and German emotional reactions, taking heart rate as a measure of emotional arousal. According to the model, German visitors 
experienced significantly higher heart rate at the stories of Sannes, Veen, Slagter, and Holvast. On the other hand, Dutch reacted with a higher heart rate to the Egger story. The stories of Inquart, Wilhelmina, and Stroink were not associated with different reactions from Dutch visitors compared to German visitors.

\section{FIGURE 3 AND TABLE 3 ABOUT HERE}

\subsection{Heart rate variability reactions to stories}

Figure 4 shows heart rate variability levels over the eight stories for Dutch and German participants. The model of heart rate variability as a function of nationality and story fit the data significantly better than a null model ( $p<0.0001$; Table 4). With this model, we aimed to identify at which stories there was a difference between reactions of Dutch and German visitors, taking heart rate variability as a measure of distress or negative emotional arousal specifically. According to the model, German visitors experienced significantly lower heart rate variability-thus, a higher level of distress - at the first five stories of the exhibit, namely the stories of Inquart, Sannes, Wilhelmina, Stroink, and Egger. The latter three stories, namely of Veen, Slagter, and Holvast were not associated with different distress reactions from Dutch visitors compared to German visitors. There was no story at which Dutch visitors experienced higher distress as measured by heart rate variability.

\section{FIGURES 4 AND 5 AND TABLE 4 ABOUT HERE}

\subsection{Self-reported emotions by story}

Figure 6 shows self-reported emotion levels over the eight stories for Dutch and German participants. In general, participants reported moderate positive (mean positive $=2.52 ; \mathrm{SD}=1.03$ ) as well as negative (mean negative $=2.40 ; \mathrm{SD}=1.09 ;$ mean bad $=2.14 ; \mathrm{SD}=1.05 ;$ mean $\mathrm{sad}=2.61 ; \mathrm{SD}=1.14$; mean angry $=2.32 ; \mathrm{SD}=$ 1.17) emotions, and the four negative emotion items used were closely related (Cronbach's $\alpha=0.87$ ). Under the Bonferroni and Benjamin-Hochberg corrections for multiple comparisons, none of the differences between Dutch and German respondents on any of the five self-reported emotion items measured are significant for any of the eight stories of the exhibit. It is worth noting that power to detect these differences was low due to the small sample size, especially among Germans, and the sample size was particularly small at certain stories which very few Germans reported visiting. Thus, we also report the T-tests that produced significant results without corrections, with the cautionary note that conclusions based on these findings carry a greater risk for Type I error. In fact, we maintain that it is more informative to look at mean differences for these instances as a measure of effect size, because some of the mean differences found are substantial. All of the reported T-tests were conducted with pooled variance estimates, in line with Levene's test results.

\section{FIGURE 6 ABOUT HERE}


Of 52 Dutch and 17 German participants, 37 Dutch and 9 German participants reported viewing the story of Queen Wilhelmina. Data show a higher mean score on the emotion positive for Dutch visitors (3.05) than German visitors (2.33), a difference which was significant at the uncorrected 0.05 level $(\mathrm{t}=2.21, \mathrm{df}=44$, $\mathrm{p}$-value $=0.032)$. Only 33 Dutch and 4 German participants reported viewing the story of Corrie Holvast. Of these, three negative emotions showed significant differences at the uncorrected 0.05 level: feeling negative $(\mathrm{t}=-2.13, \mathrm{df}=35$, $\mathrm{p}$-value $=$ $0.040)$, angry $(\mathrm{t}=-2.45, \mathrm{df}=35, \mathrm{p}$-value $=0.019)$, and $\operatorname{bad}(\mathrm{t}=-2.58, \mathrm{df}=35$, $\mathrm{p}$-value $=0.014)$. German participants felt each of these emotions more strongly (mean negative $=3.75$; mean angry $=4.00$; mean bad $=3.50$ ) than Dutch visitors (mean negative $=2.39$; mean angry $=2.36$; mean $b a d=2.06$ ). Once again, based on the uncorrected p-values and low number of German participants, these differences should be interpreted with caution (Table 5).

TABLE 5 ABOUT HERE

\section{Discussion}

In the present study, we aimed to record emotional reactions to stories of the Second World War in the Netherlands, and to explain differences in these reactions in terms of participants' nationalities as possible categories of social identity. To this end, we measured the physiological and self-reported reactions of 52 Dutch and 17 German visitors to eight stories that span the breadth of occupied Dutch society between 1941 and 1945, presented in the Overloon War Museum exhibit the Netherlands During World War II. The results showed moderate selfreported positive and negative emotional reactions, as well as varying physiological reactions in terms of heart rate and heart rate variability, with significant differences between nationalities per story.

For most of the measured stories, the three measures of emotion do not converge. We summarize the findings here per story, comparing the outcomes to the predictions suggested by social identity theory and selfcategorization theory. In previous research using cardiac measures of emotional responses, heart rate is often understood as a measure of emotion arousal in general, while heart rate variability is believed to negatively correlate with negative emotional arousal or distress in particular (Kreibig 2010; i Agustí et al. 2019). Self-reported emotions are usually analyzed in terms of positive arousal and negative arousal dimensions, an approach supported by our finding that the four negative emotion items we used were very highly correlated. Nevertheless, given that negative emotions are known to differ by group in social identity contexts related to war (Zebel et al. 2009), we analyzed each of the four negative self-response emotion items separately. After summarizing our findings per story, we show how our findings contribute to literature in three ways. First, we contrast concerns about the relevance of Second World War stories against the emotions displayed by our participants. Second, we explain what the divergent findings from physiological data mean for emotion measurement of leisure experiences. Third, we explore the meaning of the findings for social identity and self-categorization of contemporary leisure participants.

\subsection{What findings mean by story}

We expected German visitors to identify with and react more strongly to the story of Arthur Seyss-Inquart, the Nazi commissioner responsible for governing the occupied Netherlands. Consistent with this prediction, German 
visitors had lower heart rate variability at this story, suggesting greater distress. On the other hand, Dutch and German visitors had equal reactions in terms of heart rate and self-report, so the prediction cannot be conclusively supported.

We expected Dutch visitors to identify and react more strongly to the story of Arnolda Huzinga-Sannes, the aging homemaker who angrily wrote about daily wartime life in a diary. The physiological data indicated a stronger German reaction, while self-report data did not show a difference. The unexpected direction of the physiological effect suggests that the mix of positive and negative content from an explicitly Dutch narrator may have introduced some ambiguity in Dutch reactions, while the negative portrayal of the occupation may have triggered unexpected collective guilt in German visitors.

We expected Dutch visitors to positively identify with Queen Wilhelmina, as compared to a milder German reaction. This prediction was somewhat supported by the self-report data, wherein the uncorrected p-value showed a higher Dutch mean of the emotion item positive. Levels of heart rate were equal, while heart rate variability was higher among Dutch visitors, indicating the story may have been more distressing to German visitors. This difference once again points to the possibility of social group identification, with emotions of similar arousal levels occurring in both in- and out-groups, but the in-group experience of pride contrasting with the out-group experience of guilt, resentment, or perhaps another sort of negativity.

We expected to see no national differences in response to the highly ambiguous story of collaborator Gerhard Stroink. This prediction was borne out by the heart rate and self-report data, although heart rate variability was higher among Dutch visitors. It is difficult to identify a possible source for this effect, although the resolution of the story with Stroink's trial and execution may have seemed more just, and thus less distressing, to Dutch visitors.

The story of Helene Egger, a young Jewish girl, showed ambiguous effects in the physiological data, with higher arousal indicated by heart rate among Dutch visitors, yet higher distress among German visitors. The selfreport data, on the other hand, showed no national differences, as predicted. These results are generally consistent with our prediction, although they suggest a qualitative difference between the kind of emotion experienced by the two nationalities, with the reactions of German visitors being more negatively tinged.

We expected stronger, positively-driven emotional reactions from Dutch visitors to the story of Gerrit Jan van der Veen, the resistance fighter. While heart rate variability and self-report data show no national differences, heart rate showed a stronger reaction among German visitors. This finding does not support the prediction, and suggests that other, non-obvious social identification processes took place at this story.

Given that the story of interned student Wiek Slagter emphasized his youth rather than his nationality, we expected equal reactions from Dutch and German visitors. While heart rate variability and self-report data showed equal reactions, German visitors experienced relatively higher heart rate at this story. As with the story of Veen, this finding is not in line with what social identity theory would predict, and does not point to an obvious interpretation based on identifying with Slagter's nationality.

The last story of exhibition, that of starving toddler Corrie Holvast, lacks any explicit messages of national identity, consistent with our finding of equal heart rate variability. Nevertheless, heart rate and uncorrected p-values of self-report data showed stronger and more negative reactions, respectively, among German visitors. The implicit 
role of German and Dutch nationalities in her story may have triggered a sense of collective guilt mentioned in some studies of contemporary Germans (Zebel et al. 2009; Seiffge-Krenke and Haid 2012).

\subsection{Are Second World War stories still relevant?}

The context of our research was a concern in Dutch society that as the Second World War recedes into the past, younger people in particular may lose track of its meaning for the contemporary Netherlands and Europe. Cultural institutions such as the War Museum Overloon are thus using personal stories to create relevance for contemporary audiences. We asserted that such relevance, in the form of memory and behavioral consequences, is necessarily mediated by emotions (Zajchowski et al. 2016; Bastiaansen et al. 2019). If stories do not trigger emotions, they are forgotten and do not affect downstream behavior. Research on cultural heritage tourism also supports the centrality of emotions to the viability of heritage attractions (Poria et al. 2003), especially those attractions portraying war or conflict (Nawijn and Fricke 2015; Nawijn et al. 2017).

The stories of the Netherlands During World War II exhibit do induce emotional reactions in visitors. Consistent with recent research conducted at concentration camp memorials, participants reported moderate positive and negative emotions, with negative emotions rating slightly higher (Nawijn and Fricke 2015; Nawijn et al. 2017). Most of the self-reported emotions averaged near the midpoint of the five-point scale.

While they cannot be compared against an absolute scale as with self-report data, the physiological data show detectable differences from story to story, showing that participants experienced the exhibit as a process with emotional ebb and flow. These results are consistent with Bastiaansen et al.'s (2019) account of emotion during leisure experiences as an unfolding process, which varies temporally both within and across specific episodes. Our findings thus extend cross-sectional, recalled emotion measurement of war legacy leisure experiences (Gieling and Ong 2016; Nawijn et al. 2017; Nawijn and Fricke 2015; Poria et al. 2003), showing that rather than merely feeling emotion at such experiences, people go through an emotional process there. We did not examine temporal dynamics of emotion within each story, although storytelling theory offers a promising model for doing so in future research (e.g., Calvi and Hover 2015).

\subsection{Measuring emotions during leisure from multiple angles}

In general, the different emotion metrics we have collected do not all point in the same direction per story. While such results are not consistent with our predictions, they are not altogether surprising. According to previous research, heart rate reflects sympathetic activation such as arousal, and heart rate variability reflects parasympathetic de-activation such as relief, but many exceptional findings are reported (Kreibig 2010). In fact, according to Mauss and Robinson (2009), such inconsistencies do not necessarily reflect validity or reliability shortcomings in measurement. Rather, these inconsistencies reflect the complexity of emotions, whose behavioral and multiple physiological components are related and influence one another, but are not interchangeable. Furthermore, it is wellknown that self-report measures of emotion are biased by social desirability and other cognitive filtering processes (Bastiaansen et al. 2019). Based on the somewhat sensitive nature of phenomena such as collective guilt, it makes sense that physiological and self-report data would diverge in this study. Finally, the self-report data were assessed 
after participants had viewed the exhibit. Thus, participants had to cognitively reconstruct the emotions they recalled feeling. Such recall is known to diverge from what participants report nearer to the moment in question, a recall bias which was also likely responsible for differences between our self-report and physiological data (Zajchowski et al. 2016).

Our findings contribute to the growing body of ambulatory wearable measurement of emotions from tourist and leisure participants' bodies (Shoval et al. 2018; Kim and Fesenmaier 2015) in two ways. First, because emotion components do not fully overlap (Mauss and Robinson 2009), we reinforce the notion that multi-method emotion measurement is necessary to accurately record leisure experiences. Physiological measurement may be able to circumvent some cognitive biases associated with self-report, such as the difference between an experience in the moment and as it is recollected (Zajchowski et al. 2016). Second, we contribute the use of heart rate variability, which has appeared in the urban planning literature (i Agustí et al. 2019), but as far we know is novel to research on tourism, leisure, and hospitality. As our study showed, adding heart rate variability as a measure of distress next to heart rate as a measure of arousal affords more nuanced insight into emotions over the course of a leisure experience.

\subsection{Social identity and self-categorization in war stories}

Based on social identity and self-categorization theories, we predicted that stories which emphasize national identity would prompt stronger reactions from visitors with the same nationality as the main character, whereas stories which de-emphasized or ambiguated nationality would prompt equal reactions from visitors of both nationalities. These predictions were only partly supported for 2 of the 8 stories. For 3 stories, the data suggested an effect in an opposite direction than predicted; namely, a stronger German reaction where we expected a stronger Dutch one. And, for 3 stories, we found hints of a stronger German reaction when an equal reaction from both nationalities was predicted. Overall, it is clear that visitors do not simply identify with and react more strongly to the nationality emphasized in the story. Furthermore, even when some stories instead emphasize the superordinate category, humanity, nationality continues to play a role in visitor reactions.

From the present data it is not possible to distinguish how visitors' nationality triggers different emotional reactions to stories which emphasize characters' humanity. However, the general direction of the differencestronger, and especially more negative, among German visitors - points in the direction of collective guilt. The persistence of collective guilt about Second World War events to contemporary German society has been well documented (Wohl and Branscombe 2004; Seiffge-Krenke and Haid 2012). Future research should examine whether these stories do in fact trigger collective guilt, and bring to light what other emotional processes may be at play. Perhaps more importantly, the behavioral outcomes of these various emotions should be assessed, such as forgiveness and willingness toward reconciliation, which are common in the social identity literature (Shnabel et al. 2009; Zebel et al. 2009). In designing leisure experiences around the legacy of the Second World War, cultural institutions in the Netherlands view emotions as a means to an end, with pro-social behavior aligned with the values of peace, democracy, and self-determination being the ultimate goal. More research is needed to determine if emotions mediate impact of leisure experiences on such goals over the longer term. 
Our finding that national differences in emotional reactions to Second World War stories are more complex than predicted by straightforward applications of social identity and self-categorization theories does not invalidate these theories. The social identity framework remains "a robust theory of human social behavior with implications for leisure research" (Mueller et al. 2019, p.96). Rather, in line with previous research applying social identity theory to leisure, we show that leisure experiences are complex not only in emotions, but in the social identity processes they trigger.

\subsection{Limitations}

We undertook a challenging, technically complex data collection in the present study which introduced some limitations into the data. The most important limitation is the small and unbalanced sample, with relatively few German participants. This sample made it difficult to statistically detect national differences, and precluded more complex examinations of between-participant differences, for example based on gender and age. Furthermore, we cannot exclude that, despite careful cleaning of the data and exclusion of participants with unrealistic physiological values, that the motion of walking around the exhibit introduced noise which may have affected the results. Finally, given that very low numbers of participants reported visiting some stories, it is possible that the self-report data were affected by an inability to recall or identify which stories they had visited.

\section{Conclusion}

In the present paper, we set out to examine the effect of national identities on emotional processing of Second World War stories. The context for the research is framed by concerns in the Netherlands that the war may no longer be seen as "living history," with relevant lessons for the present. We posited that the issue of nationality served an ambiguous role in this context — on one hand, a potential lesson of the war could be that supraordinate categories such as humanity would be more important than nationality; on the other hand, not identifying with the nationality of historical characters could be one indicator of not identifying with stories from so long ago in general. While more research is needed to untangle this ambiguity, our physiological and self-report measurement of emotional reactions at an exhibit of Second World War stories offers several preliminary conclusions on this issue. First, the mixed emotions in the stories were reflected in emotionally mixed self-reports by respondents. Such an exhibit is not universally pleasant or upsetting, but was certainly emotionally engaging for our participants. Second, physiological reactions differed from self-reported reactions, suggesting that these signals measure different components of emotional experience. Third, neither physiological nor self-reported emotional reactions followed patterns that a straightforward application of social identity theory and self-categorization theory would predict. Thus, neither historical nationality nor humanity transfers from Second World War history to the contemporary leisure participant in a straightforward way.

We would like to conclude with an optimistic interpretation of the latter conclusion. The fact that participants clearly reacted emotionally to the exhibit, yet national membership does not lead to obvious social identity effects, suggests that Second World War stories are still relevant without triggering historical nationalist instincts. Thus, we cautiously hope that contemporary Europeans engage with stories of the Second World War to 
inform their understanding of present-day society with their minds open beyond singular national identities. Stebbins (2018) recently asserted in this journal that leisure has a positive role in society. There is reason to see the efforts of leisure institutions in the Netherlands to make Second World Stories relevant for contemporary audiences as part of this positive role. 
Table 1

Summary of stories in the Netherlands During World War II

\begin{tabular}{|c|c|c|c|c|c|c|c|c|}
\hline Name & $\begin{array}{l}\text { Arthur } \\
\text { Seyss- } \\
\text { Inquart }\end{array}$ & $\begin{array}{l}\text { Arnolda } \\
\text { Huzinga- } \\
\text { Sannes }\end{array}$ & $\begin{array}{l}\text { Queen } \\
\text { Wilhelmina }\end{array}$ & $\begin{array}{l}\text { Gerhard } \\
\text { Stroink }\end{array}$ & $\begin{array}{l}\text { Helene } \\
\text { Egger }\end{array}$ & $\begin{array}{l}\text { Gerrit Jan } \\
\text { van der } \\
\text { Veen }\end{array}$ & $\begin{array}{l}\text { Wiek } \\
\text { Slagter }\end{array}$ & $\begin{array}{l}\text { Corrie } \\
\text { Holvast }\end{array}$ \\
\hline Display format & $\begin{array}{l}\text { Interactive } \\
\text { audio }\end{array}$ & $\begin{array}{l}\text { Interactive } \\
\text { audio }\end{array}$ & $\begin{array}{l}\text { Interactive } \\
\text { audio }\end{array}$ & $\begin{array}{l}\text { Interactive } \\
\text { video }\end{array}$ & Video & $\begin{array}{l}\text { Interactive } \\
\text { video }\end{array}$ & $\begin{array}{l}\text { Interactive } \\
\text { video/audio }\end{array}$ & $\begin{array}{l}\text { Interactive } \\
\text { video }\end{array}$ \\
\hline $\begin{array}{l}\text { In-group } \\
\text { identity of } \\
\text { character }\end{array}$ & German & Dutch & Dutch & Ambiguous & $\begin{array}{l}\text { Human, } \\
\text { child, } \\
\text { Jewish }\end{array}$ & Dutch & $\begin{array}{l}\text { Student, } \\
\text { young, } \\
\text { male }\end{array}$ & $\begin{array}{l}\text { Child, } \\
\text { human }\end{array}$ \\
\hline $\begin{array}{l}\text { In-group } \\
\text { connotation }\end{array}$ & Negative & Positive & Positive & Ambiguous & Positive & Positive & Positive & Positive \\
\hline $\begin{array}{l}\text { Hypothesized } \\
\text { reaction }\end{array}$ & $\begin{array}{l}\text { Stronger } \\
\text { German } \\
\text { reaction }\end{array}$ & $\begin{array}{l}\text { Stronger } \\
\text { Dutch } \\
\text { reaction }\end{array}$ & $\begin{array}{l}\text { Stronger } \\
\text { Dutch } \\
\text { reaction }\end{array}$ & Equal & Equal & $\begin{array}{l}\text { Stronger } \\
\text { Dutch } \\
\text { reaction }\end{array}$ & Equal & Equal \\
\hline
\end{tabular}


Table 2

Descriptive statistics of the demographic variables

\begin{tabular}{lcc}
\hline Variable & Category & N \\
\hline Gender & Male & \\
& Female & 40 \\
\hline Nationality & Dutch & 29 \\
& German & 52 \\
\hline Age & $18-25$ & 17 \\
$(\mathrm{M}=40,4, \mathrm{SD}=12,79)$ & $26-35$ & 11 \\
& $36-50$ & 12 \\
& $>51$ & 33 \\
\hline Previous visits & 0 & 13 \\
& $1-3$ & 38 \\
& $4-6$ & 24 \\
\hline
\end{tabular}




\section{Table 3}

Models of physiological emotional reactions in heart rate as functions of story $x$ nationality interactions

\begin{tabular}{|c|c|c|c|c|c|}
\hline Outcome & Predictor & $\begin{array}{c}\text { Coefficient } \\
\text { estimate }\end{array}$ & SE & $\mathrm{T}$ & Model AIC \\
\hline \multirow[t]{19}{*}{ Heart rate } & & & & & 1455134 \\
\hline & (Intercept) & 81.470 & 1.233 & $66.085^{* * *}$ & \\
\hline & Nationality & 1.976 & 2.424 & 0.815 & \\
\hline & Inquart & -0.227 & 0.138 & $-2.013^{*}$ & \\
\hline & Sannes & -1.460 & 0.162 & $-9.030 * * *$ & \\
\hline & Wilhelmina & -0.448 & 0.118 & $-3.794 * * *$ & \\
\hline & Stroink & -1.871 & 0.094 & $-19.811 * * *$ & \\
\hline & Egger & -0.004 & 0.116 & -0.030 & \\
\hline & Veen & -1.349 & 0.112 & $-12.045^{* * *}$ & \\
\hline & Slagter & -1.13 & 0.186 & $-6.072 * * *$ & \\
\hline & Holvast & 0.945 & 0.127 & $7.440 * * *$ & \\
\hline & Inquart x Nationality & 0.205 & 0.328 & 0.624 & \\
\hline & Sannes x Nationality & 7.314 & 0.416 & $17.565 * * *$ & \\
\hline & Wilhelmina $\mathrm{x}$ Nationality & 0.448 & 0.350 & 1.281 & \\
\hline & Stroink x Nationality & -0.003 & 0.216 & -0.150 & \\
\hline & Egger x Nationality & -2.439 & 0.342 & $-7.124 * * *$ & \\
\hline & Veen $x$ Nationality & 13.850 & 0.284 & $48.763 * * *$ & \\
\hline & Slagter x Nationality & 4.746 & 0.345 & $13.766^{* * *}$ & \\
\hline & Holvast $\mathrm{x}$ Nationality & 1.644 & 0.429 & $3.837 * * *$ & \\
\hline
\end{tabular}

Notes: Signif. codes: $0{ }^{\prime * * * 1} 0.001^{\prime * * 1} 0.01^{\prime * 1} 0.05^{\prime . '} 0.1^{\prime}{ }^{\prime} 1$. 


\section{Table 4}

Models of physiological emotional reactions in heart rate variability as functions of story $x$ nationality interactions

\begin{tabular}{|c|c|c|c|c|c|}
\hline Outcome & Predictor & $\begin{array}{l}\text { Coefficient } \\
\text { estimate }\end{array}$ & SE & $\mathrm{T}$ & Model AIC \\
\hline \multirow{19}{*}{$\begin{array}{l}\text { Heart rate } \\
\text { variability }\end{array}$} & & & & & -1512906.3 \\
\hline & (Intercept) & 0.005531 & 0.000248 & $22.305 * * *$ & \\
\hline & Inquart & 0.000596 & 0.000060 & $9.870 * * *$ & \\
\hline & Nationality & -0.000089 & 0.000488 & -0.182 & \\
\hline & Sannes & 0.000026 & 0.000071 & 0.365 & \\
\hline & Wilhelmina & -0.000208 & 0.000052 & $-4.010 * * *$ & \\
\hline & Stroink & -0.000505 & 0.000041 & $-12.177 * * *$ & \\
\hline & Egger & 0.000191 & 0.000051 & $3.731 * * *$ & \\
\hline & Veen & -0.000112 & 0.000049 & $-2.269 *$ & \\
\hline & Slagter & 0.000678 & 0.000082 & $8.293 * * *$ & \\
\hline & Holvast & -0.000146 & 0.000056 & $-2.624 * *$ & \\
\hline & Inquart $\mathrm{x}$ Nationality & -0.000815 & 0.000145 & $-5.638 * * *$ & \\
\hline & Sannes x Nationality & -0.001294 & 0.000183 & $-7.083 * * *$ & \\
\hline & Wilhelm x Nationality & -0.000715 & 0.000154 & $-4.653 * * *$ & \\
\hline & Stroink x Nationality & -0.000462 & 0.000095 & $-4.883 * * *$ & \\
\hline & Egger x Nationality & -0.000452 & 0.000150 & $-3.017 * *$ & \\
\hline & Veen $\mathrm{x}$ Nationality & -0.000066 & 0.000125 & -0.526 & \\
\hline & Slagter x Nationality & 0.000195 & 0.000151 & 1.285 & \\
\hline & Holvast x Nationality & 0.000164 & 0.000188 & 0.873 & \\
\hline
\end{tabular}

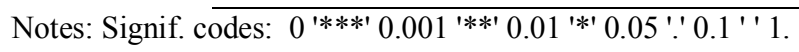




\section{Table 5}

T-tests of self-report emotions with significant Dutch-German differences at the uncorrected 0.05 level

\begin{tabular}{|c|c|c|c|c|c|}
\hline Story & Emotion & $\begin{array}{l}\text { Mean difference on 5-point } \\
\text { scale (Dutch-German) }\end{array}$ & $\mathrm{T}$ & Uncorrected p-value & $\begin{array}{l}\text { Critical value for } p \\
\text { under Benjamin- } \\
\text { Hochberg correction }\end{array}$ \\
\hline \multicolumn{6}{|c|}{ Wilhelmina } \\
\hline & Positive & 0.72 & 2.21 & 0.032 & 0.01875 \\
\hline \multicolumn{6}{|l|}{ Holvast } \\
\hline & Negative & -1.36 & -2.13 & 0.040 & 0.025 \\
\hline & Angry & -1.64 & -2.45 & 0.019 & 0.0125 \\
\hline & $\mathrm{Bad}$ & -1.44 & -2.58 & 0.014 & 0.00625 \\
\hline
\end{tabular}

Notes: $\mathrm{N}=37$ Dutch and 9 German at the Wilhelmina story and 33 Dutch and 4 German at the Holvast story. 


\section{Figure 1}

Impression of the Netherlands during World War II exhibit, showing the exterior of the Gerrit Jan van der Veen display

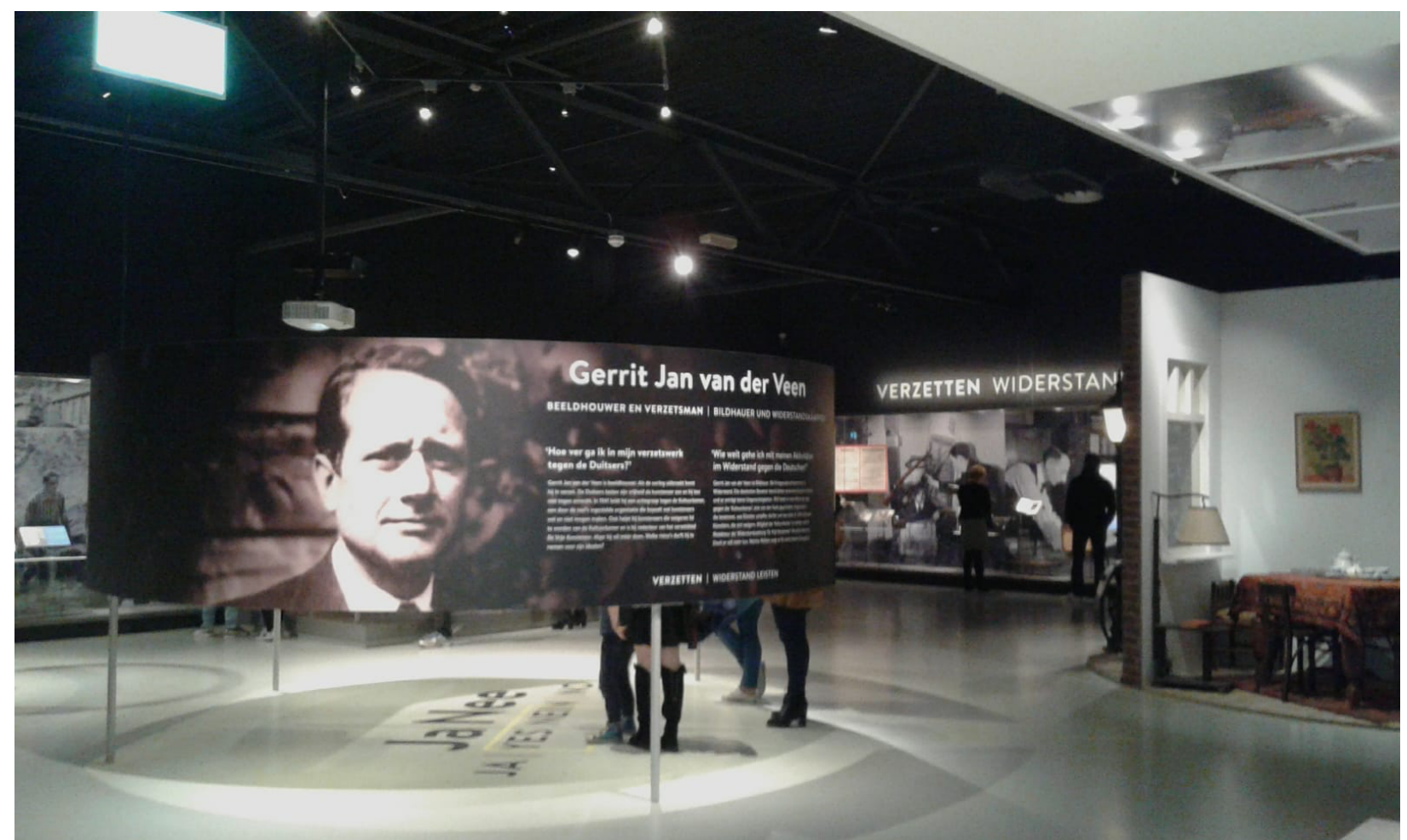


Figure 2

Map of stories within the Netherlands during World War II exhibit

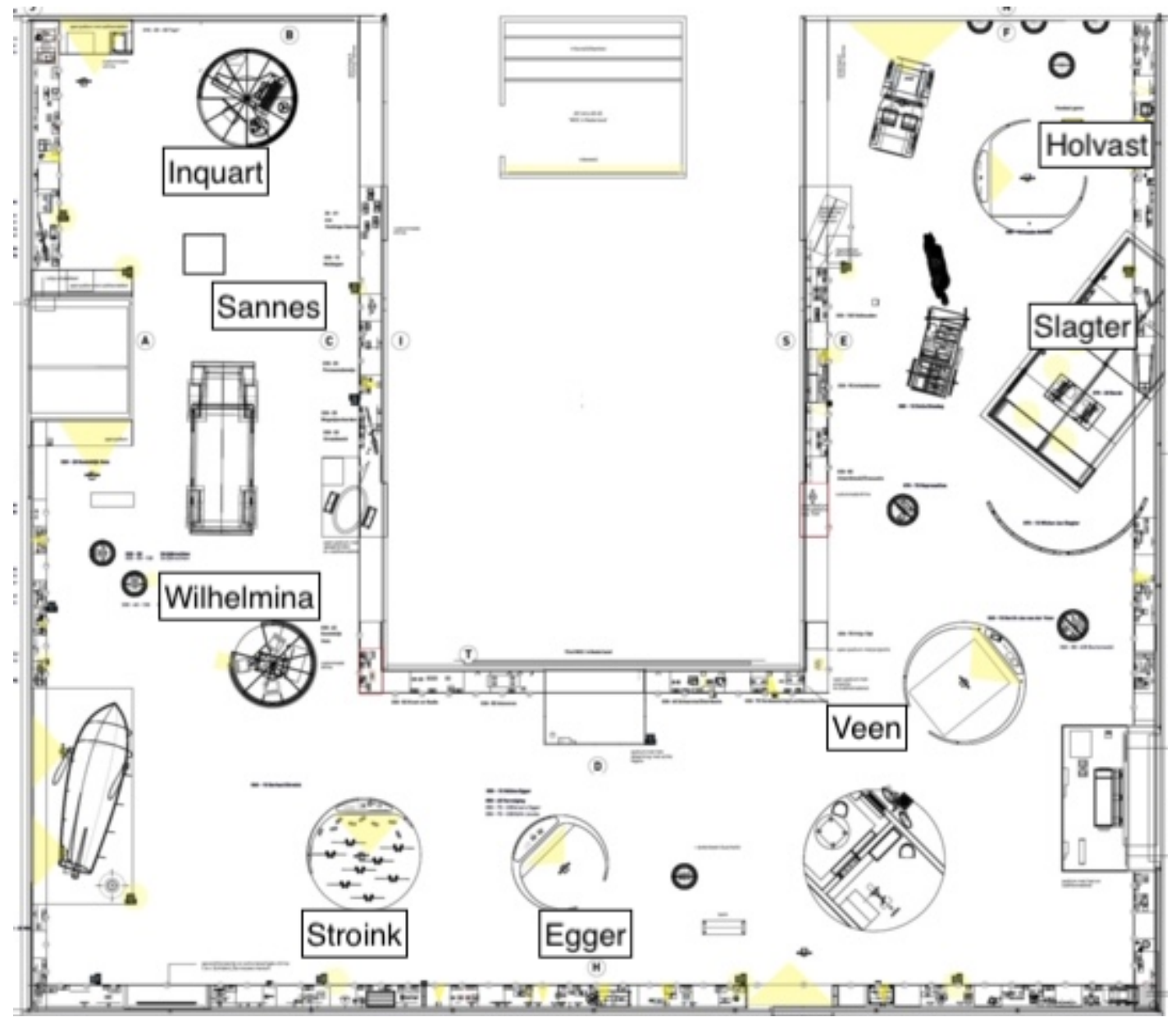


Figure 3

Heart rate per story by nationality

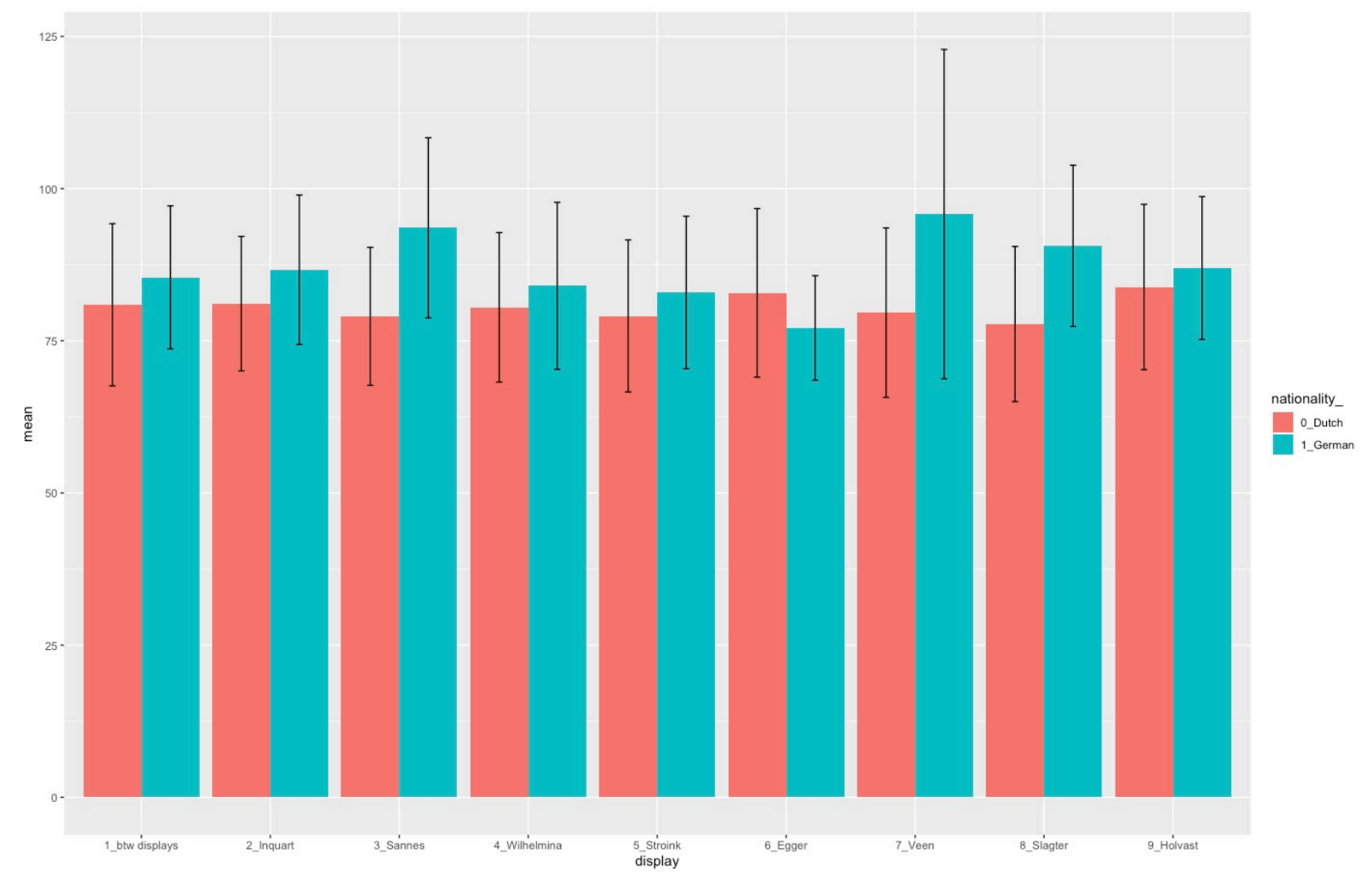


Figure 4

Heart rate variability per story by nationality

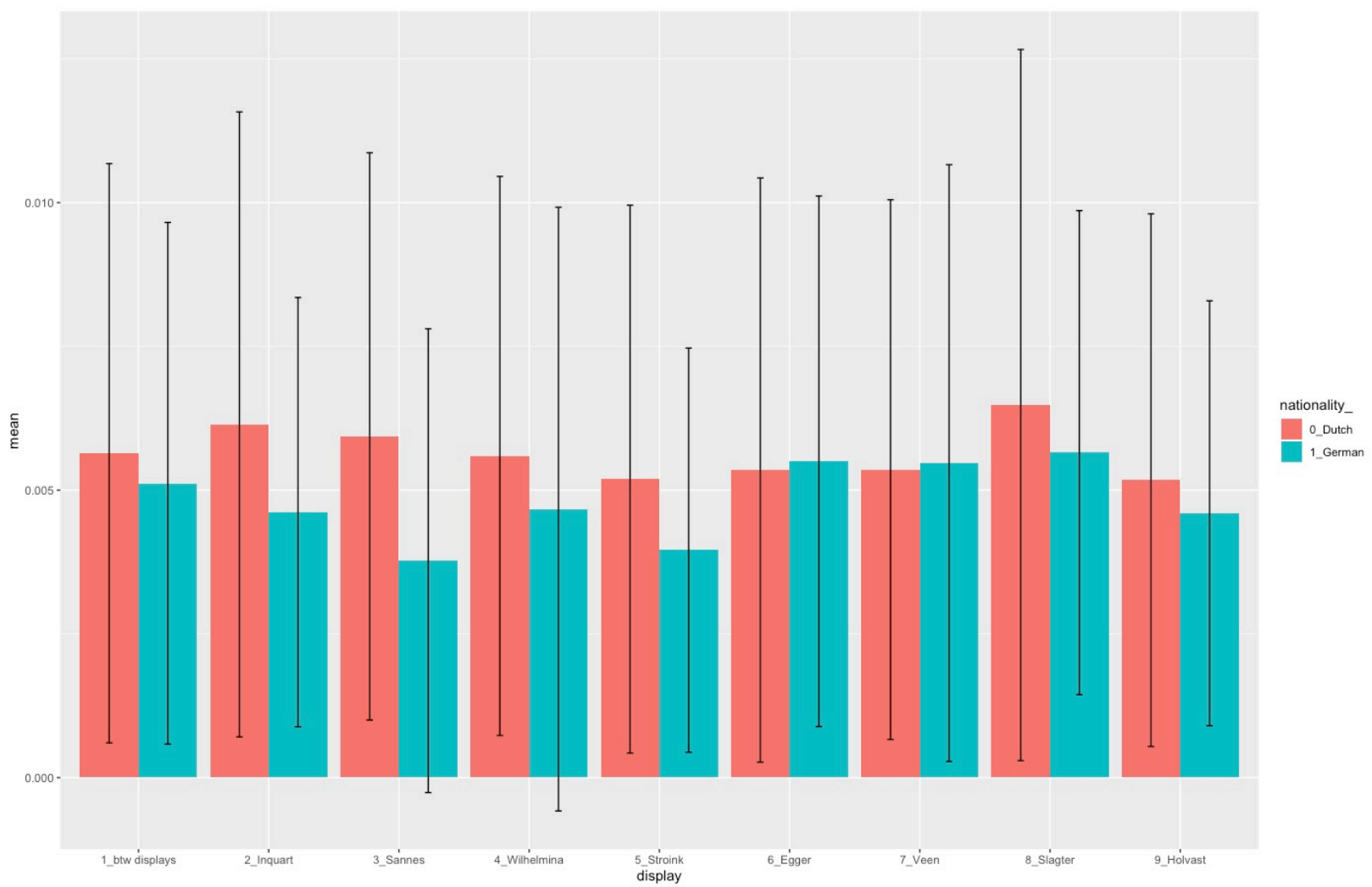




\section{Figure 5}

Heart rate and heart rate variability maps of exhibit
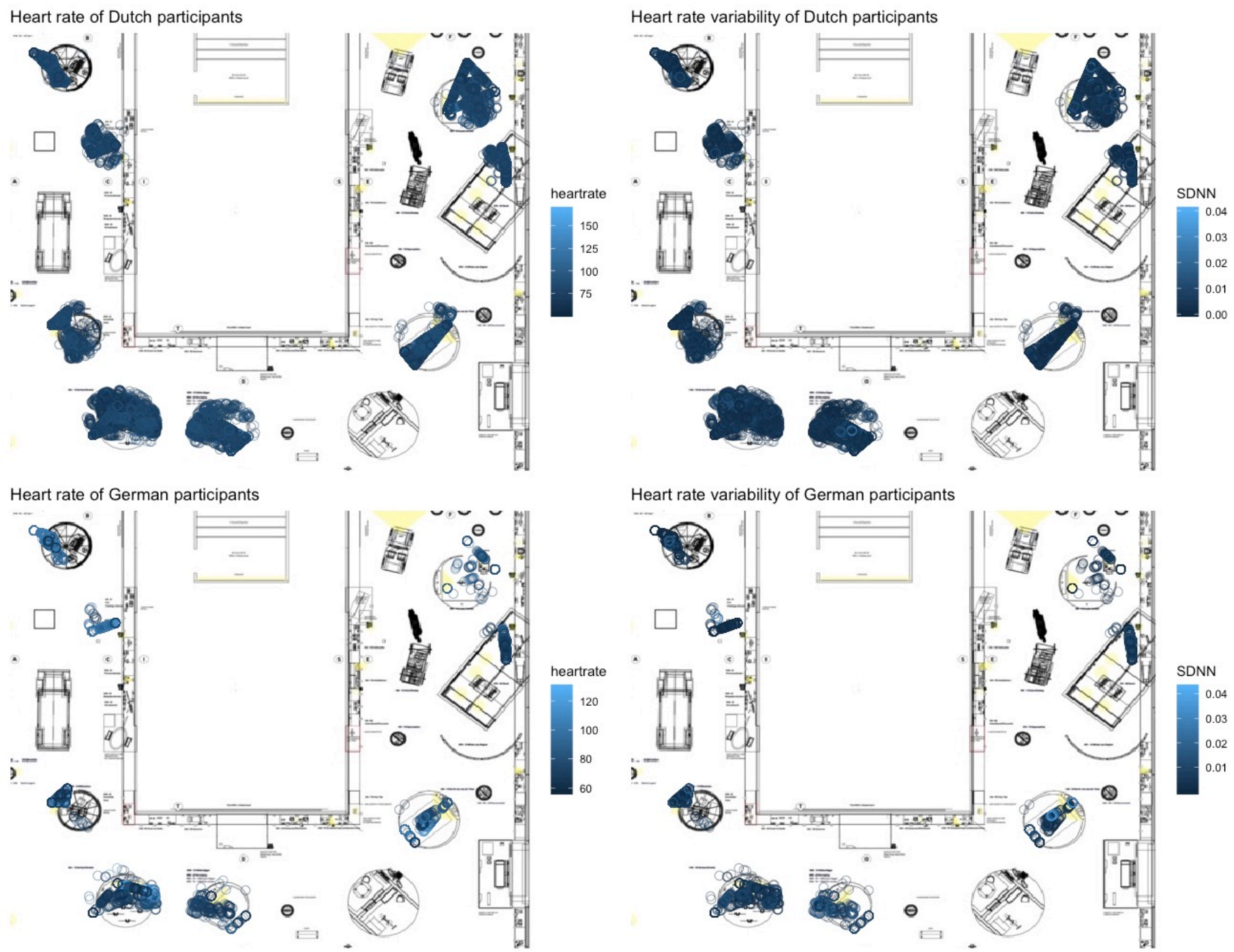
Figure 6

Means of self-reported emotions per story by nationality 

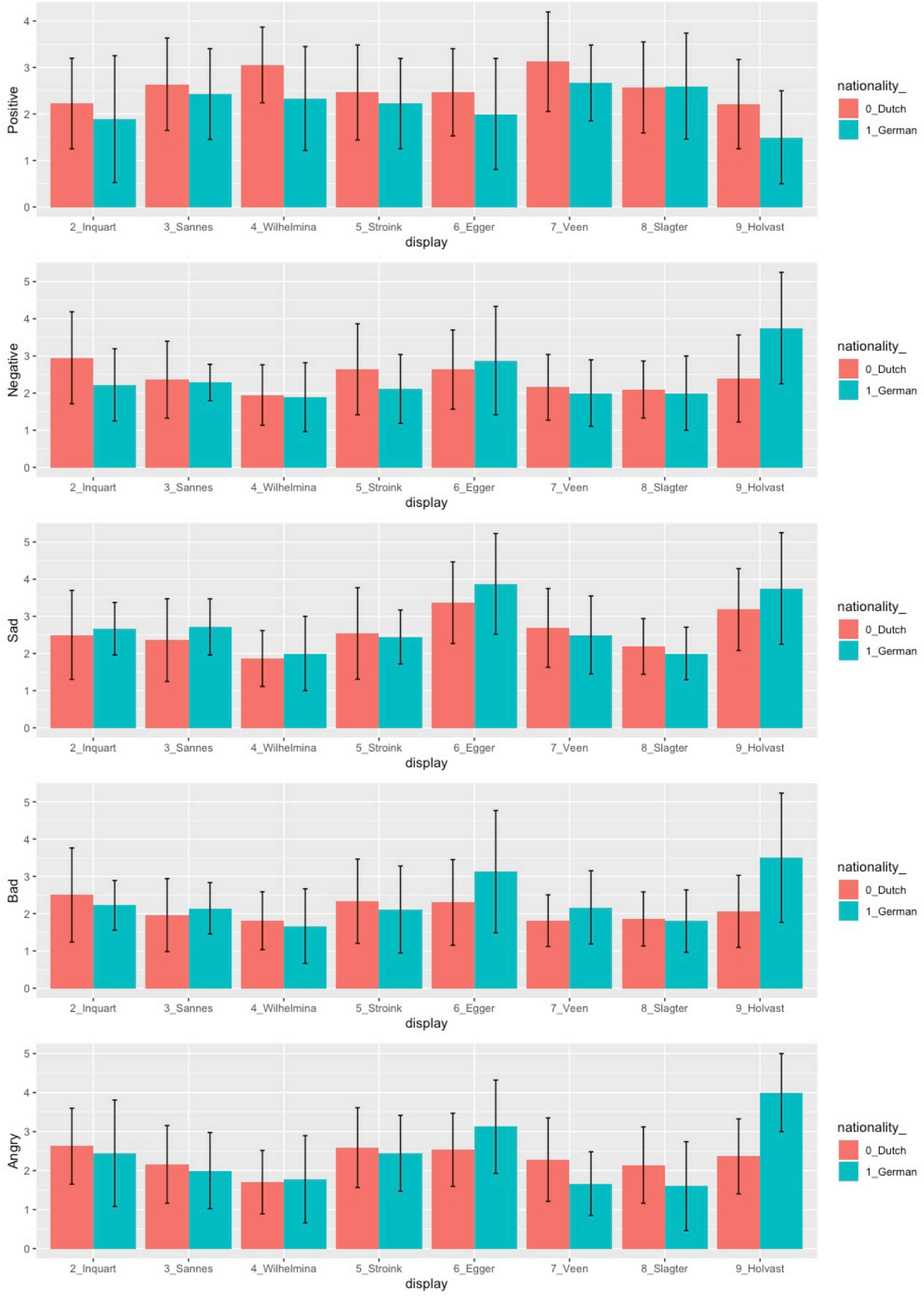


\section{References}

Abrams, D., \& Hogg, M. A. (2010). Social identity and self-categorization: The SAGE handbook of prejudice, stereotyping and discrimination.

Ashforth, B. E., \& Mael, F. (1989). Social identity theory and the organization. Academy of management review, 14(1), 20-39.

Bastiaansen, M., Lub, X., Mitas, O., Jung, T. H., Passos Acenção, M., Han, D., et al. (2019). Emotions as core building blocks of an experience. International Journal of Contemporary Hospitality Management, 31.

Cacioppo, J. T., Tassinary, L. G., \& Berntson, G. (2007). Handbook of psychophysiology: Cambridge university press.

Calvi, L., \& Hover, M. (2015). Becoming Vincent: Using storytelling to link Vincent van Gogh's heritage sites physically and digitally. Vaugeois, N., Parker, P., \& Weighill, A.(Eds.).(2015). Innovative leisure practices: Cases as conduits between theory and practice. Nanaimo, BC: World Leisure Centre of Excellence in Sustainability and Innovation at Vancouver Island University.

Diener, E., Wirtz, D., Tov, W., Kim-Prieto, C., Choi, D.-w., Oishi, S., et al. (2010). New well-being measures: Short scales to assess flourishing and positive and negative feelings. Social Indicators Research, 97(2), 143-156.

Duerden, M. D., Ward, P. J., \& Freeman, P. A. (2015). Conceptualizing structured experiences: Seeking interdisciplinary integration. Journal of Leisure Research, 47(5), 601-620.

Field, A., Miles, J., \& Field, Z. (2012). Discovering statistics using R. London: Sage publications.

Gieling, J., \& Ong, C.-E. (2016). Warfare tourism experiences and national identity: The case of Airborne Museum 'Hartenstein'in Oosterbeek, the Netherlands. Tourism Management, 57, 45-55.

Hartmann, R. (2014). Dark tourism, thanatourism, and dissonance in heritage tourism management: New directions in contemporary tourism research. Journal of Heritage Tourism, 9(2), 166-182.

Hogg, M. A., Terry, D. J., \& White, K. M. (1995). A tale of two theories: A critical comparison of identity theory with social identity theory. Social psychology quarterly, 255-269.

Hornsey, M. J. (2008). Social identity theory and self-categorization theory: A historical review. Social and Personality Psychology Compass, 2(1), 204-222.

i Agustí, D. P., Rutllant, J., \& Fortea, J. L. (2019). Differences in the perception of urban space via mental maps and Heart Rate Variation (HRV). Applied Geography, 112, 102084.

Jones, I. (2000). A model of serious leisure identification: The case of football fandom. Leisure Studies, 19(4), 283298.

Kim, J., \& Fesenmaier, D. R. (2015). Measuring emotions in real time: Implications for tourism experience design. Journal of Travel Research, 54(4), 419-429.

Kreibig, S. D. J. B. p. (2010). Autonomic nervous system activity in emotion: A review. 84(3), 394-421.

Laverie, D. A., \& Arnett, D. B. (2000). Factors affecting fan attendance: The influence of identity salience and satisfaction. Journal of Leisure Research, 32(2), 225-246.

Liu, H.-L., Bradley, M. J., \& Burk, B. (2016). I am roller derby: the serious leisure and leisure identity of roller derby participants. World Leisure Journal, 58(1), 28-43.

Mauss, I. B., \& Robinson, M. D. (2009). Measures of emotion: A review. Cognition \& emotion, 23(2), 209-237.

McDonald, J. H. (2014). Handbook of Biological Statistics (3rd. ed.). Baltimore, Maryland: Sparky House Publishing.

Mitas, O., Nawijn, J., \& Jongsma, B. (2017). Between Tourists: Tourism and Happiness. In M. K. Smith, \& L. Puczko (Eds.), The Routledge Handbook of Health Tourism (pp. 47-64). London: Routledge.

Mitas, O., Qian, X. L., Yarnal, C., \& Kerstetter, D. (2011). " The Fun Begins Now!": Broadening and Building Processes in Red Hat Society ${ }^{\circledR}$ Participation. Journal of Leisure Research, 43(1), 30.

Mueller, J. T., Landon, A. C., \& Graefe, A. R. (2019). Modeling the role of social identity in constraint negotiation for ultra-endurance gravel cycling. Journal of Leisure Research, 50(2), 81-106.

Nawijn, J., Brüggemann, M., \& Mitas, O. (2017). The Effect of Sachsenhausen Visitors' Personality And Emotions on Meaning and Word of Mouth. Tourism Analysis, 22(3), 349-359.

Nawijn, J., \& Fricke, M. C. (2015). Visitor emotions and behavioral intentions: The case of concentration camp memorial Neuengamme. International Journal of Tourism Research, 17(3), 221-228.

Poppe, E. (2001). Effects of changes in GNP and perceived group characteristics on national and ethnic stereotypes in Central and Eastern Europe 1. Journal of Applied Social Psychology, 31(8), 1689-1708.

Poria, Y., Butler, R., \& Airey, D. (2003). The core of heritage tourism. Annals of tourism research, 30(1), $238-254$. 
Risse, T. (2001). A European identity? Europeanization and the evolution of nation-state identities. In M. G. Cowles, J. A. Caporaso, \& T. Risse (Eds.), Transforming Europe: Europeanization and domestic change (pp. 198-216). Ithaca, NY: Cornell University Press.

Rosenberg, E. L. (1998). Levels of analysis and the organization of affect. Review of general psychology, 2(3), 247270.

Seiffge-Krenke, I., \& Haid, M. L. (2012). Identity development in German emerging adults: Not an easy task. New directions for child and adolescent development, 2012(138), 35-59.

Shnabel, N., Nadler, A., Ullrich, J., Dovidio, J. F., \& Carmi, D. (2009). Promoting reconciliation through the satisfaction of the emotional needs of victimized and perpetrating group members: The needs-based model of reconciliation. Personality and Social Psychology Bulletin, 35(8), 1021-1030.

Shoval, N., Schvimer, Y., \& Tamir, M. (2018). Real-time measurement of tourists' objective and subjective emotions in time and space. Journal of Travel Research, 57(1), 3-16.

Stebbins, R. A. (2018). The sociology of leisure: An estranged child of mainstream sociology. International Journal of the Sociology of Leisure, 1(1), 43-53.

Stets, J. E., \& Burke, P. J. (2000). Identity theory and social identity theory. Social psychology quarterly, 224-237.

Stodolska, M., \& Tainsky, S. (2015). Soccer spectatorship and identity discourses among Latino immigrants. Leisure Sciences, 37(2), 142-159.

Tajfel, H. (1974). Social identity and intergroup behaviour. Information (International Social Science Council), 13(2), 65-93.

Tajfel, H. (1979). Individuals and groups in social psychology. British Journal of Social and Clinical Psychology, 18(2), 183-190.

Turner, J. C., Hogg, M. A., Oakes, P. J., Reicher, S. D., \& Wetherell, M. S. (1987). Rediscovering the social group: A self-categorization theory: Basil Blackwell.

Wirtz, D., Kruger, J., Scollon, C. N., \& Diener, E. (2003). What to do on spring break? The role of predicted, online, and remembered experience in future choice. Psychological Science, 14(5), 520-524.

Wohl, M. J., \& Branscombe, N. R. (2004). Importance of social categorization for forgiveness and collective guilt assignment for the Holocaust. In N. R. Branscombe, \& B. Doosje (Eds.), Collective guilt: International perspectives (pp. 284-305). Cambridge, UK: Cambridge University Press.

Wohl, M. J., \& Branscombe, N. R. (2005). Forgiveness and collective guilt assignment to historical perpetrator groups depend on level of social category inclusiveness. Journal of personality and social psychology, $88(2), 288$.

Zajchowski, C. A., Schwab, K. A., \& Dustin, D. L. (2016). The Experiencing Self and the Remembering Self: Implications for Leisure Science. Leisure Sciences, 1-8.

Zebel, S., Doosje, B., \& Spears, R. (2009). How perspective-taking helps and hinders group-based guilt as a function of group identification. Group Processes \& Intergroup Relations, 12(1), 61-78. 